\title{
¿VIOLENCIA POLÍTICA O DELINCUENCIA COMÚN? LOS SUCESOS DE JEREZ Y ARCOS DE PRINCIPIOS DE 1936
}

\author{
POLITICAL VIOLENCE OR CRIME? THE EVENTS OF JEREZ \\ AND ARCOS AT THE BEGINNING OF 1936. \\ Diego Caro Cancela*, Antonio Ortega Castillo \\ Universidad de Cádiz. España
}

\begin{abstract}
RESUMEN: En este artículo se cuestionan los datos que algunos historiadores han dado sobre la supuesta elevada violencia política que se produce en España desde principios de 1936 y hasta el triunfo del Frente Popular. Se considera que se mezclan incidentes de variopintas motivaciones, algunos de los cuales nada tienen que ver con política. Partiendo del análisis detallado de un caso concreto - la actuación de un grupo de pistoleros que en dos días provocan cuatro muertes - se plantea la tesis de que estas acciones tenían más que ver con la delincuencia común que con cualquier tipo de planteamiento político o social.

PALABRAS CLAVE: Violencia política, delincuencia, Segunda República, Jerez de la Frontera, Arcos de la Frontera.

ABSTRACT: In this article, we call into question the data that some historians have given on the so-called high political violence that occurs in Spain beginning in 1936 and until the triumph of the Popular Front. We consider they mix incidents of varied motivations, some of which have nothing to do with politics. On the basis of the detailed analysis of a specific case-the performance of a group of gunmen around two days that caused four deaths - we bring the thesis that these actions had more to do with crime than any type of political or social approach.
\end{abstract}

KEY WORDS: Political violence, crime, Second Republic, Jerez de la Frontera, Arcos de la Frontera.

* Correspondencia a: Diego Caro Cancela. Universidad de Cádiz. Facultad de Filosofía y Letras. Departamento Historia Moderna, Contemporánea, de América y del Arte. Av. Gómez Ulla s/n. 11003 Cádiz. (Spain) - diego.caro@uca.es - https:// orcid.org/0000-0002-4626-6555

Cómo citar: Caro Cancela, Diego; Ortega Castillo, Antonio (2021). «Violencia política o delincuencia común? Los sucesos de Jerez y Arcos de principios de 1936»; Historia Contemporánea, 65, 101-130. (https://doi.org/10.1387/hc.21000).

Recibido: 10 julio, 2019; aceptado: 29 octubre, 2019.

ISSN 1130-2402 - eISSN 2340-0277 / (C) 2020 UPV/EHU

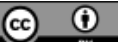

Esta obra está bajo una licencia

Creative Commons Atribución 4.0 Internacional 


\section{Introducción}

En la noche del 17 de enero de 1936, tres pistoleros disparaban contra las personas que se encontraban en el interior de un tabanco en una plaza del centro de Jerez de la Frontera y causaban la muerte de un obrero tonelero y heridas graves a un agente de la Guardia Civil y al subjefe de la Policía Municipal de la ciudad. Al día siguiente, los autores de los disparos eran localizados en una taberna de la vecina población de Arcos de la Frontera, produciéndose un tiroteo con las fuerzas policiales que iban a detenerlos, resultando muertos dos de estos individuos, un alférez de la Guardia Civil, quedando también herido el tercero que les acompañaba. La prensa de extrema derecha de aquellos días no tardó en presentar estos hechos como producto de la agitación social con la que las izquierdas iban a concurrir a las elecciones, dándole una clara motivación política a los mismos, un argumento recogido por la reciente historiografía de corte revisionista. Como pretendemos demostrar a continuación, - partiendo de un caso que tuvo una enorme repercusión - hubo una serie de incidentes en la «precampaña» y en la «campaña» de las conocidas como «elecciones del Frente Popular» que estuvieron protagonizados por individuos o grupos que nada tenían que ver con este proceso electoral. Se trataron de actuaciones que se movían entre una difusa adscripción a las organizaciones anarquistas y la delincuencia común, resultando difícil de discernir cuando se actuaba con una motivación social «a favor» de los trabajadores y cuando se hacía por puro interés particular o buscando el beneficio propio.

Como veremos en primer lugar, la conducta de los llamados «grupos de acción» durante la Segunda República no era novedosa, sino que procedía de los años veinte cuando el fenómeno del pistolerismo tomó fuerza en España y especialmente en Cataluña. A continuación, describiremos la doble militancia que tuvieron algunos conocidos militantes de la CNT en los años republicanos. Por un lado, en las organizaciones obreras, a la luz pública y, por otro, en estos «cuadros de defensa» o «de acción» que se movían en la clandestinidad. Del mismo modo, veremos cómo en estas bandas armadas encontraron refugio o cobertura personas que se movían también en los ambientes marginales de la delincuencia o el hampa y que hicieron del pistolerismo una forma de vida. En tercer lugar, comentaremos los hechos concretos que tienen lugar en Jerez y en Arcos a mediados de enero de 1936 y la valoración que la principal organización obrera anarquista de esta última población hizo de los mismos. Y, por último, 
¿Violencia política o delincuencia común? Los sucesos de Jerez y Arcos de principios...

analizaremos la actitud de las autoridades republicanas ante el único individuo del grupo que sobrevivió, y cómo se negaron a que se pudiera beneficiar de las medidas de gracia que se aprobaron después del triunfo frentepopulista, en contra de lo que pedían las organizaciones vinculadas a la CNT, claramente favorables a través de su prensa de que las mismas se ampliaran para acoger a los que estaban presos acusados de cometer delitos comunes.

\section{La anarquía republicana como justificación del golpe de Estado}

Es conocido que los dos argumentos principales que los golpistas de 1936 emplearon para justificar su acción contra la democracia republicana fueron, por un lado, el ambiente anarquía y caos que se vivía en España desde que el Frente Popular ganara las elecciones de febrero y, por otro, el evitar la ejecución de un presunto plan para establecer en España un régimen comunista al estilo del que entonces existía en la Unión Soviética. Pero si este segundo argumento prontamente quedó desacreditado por la historiografía cuando todavía se mantenía la dictadura franquista, no ocurrió lo mismo con el de la violencia y la anarquía que acompañó al triunfo de las izquierdas ${ }^{1}$. Aunque arrancó ya en 1939, cuando Serrano Suñer hizo publicar su conocido «dictamen» sobre la «ilegitimidad» de origen del gobierno frentepopulista, al ser el resultado de unas elecciones fraudulentas y violentas, en tiempos más bien recientes hemos tenido que volver a leer, no sin sorpresa, la reproducción casi mimética del relato de la historia que se tejió hace ochenta años, eso sí, ahora envueltos en pretendidos ropajes académicos.

Ha escrito Eduardo González Calleja, que «durante la guerra y la posguerra, la violencia política, identificada con la anarquía y la revolución inherentes al régimen republicano, constituyó la principal base justificativa del Alzamiento nacional» ${ }^{2}$. No obstante, en las tres últimas décadas no han sido pocos los avances que se han producido en la historiografía centrada en esta cuestión, desde que a mediados de los años ochenta del pasado siglo, Julio Aróstegui abriera lo que entonces era una novedosa línea de investigación, continuada en años posteriores por autores como el

\footnotetext{
1 Sobre estos documentos falsos del «complot» comunista: Southworth, 2000, especialmente las páginas 13-186.

${ }^{2}$ González, 2013, p. 408. Consulta realizada el 16 de mayo de 2019.
} 
citado González Calleja, Santos Juliá, Rafael Cruz y por el grupo coordinado por Fernando del Rey ${ }^{3}$. Sin embargo, a pesar de estas aportaciones y de los nuevos enfoques metodológicos empleados, todavía no se ha delimitado claramente el campo de lo que constituye un claro ejercicio de violencia política y lo que pudiéramos considerar como «violencia social», de lo que entraría en el ámbito de los considerados como delitos comunes en el mundo difuso que se crea en los grupos armados que actúan bajo la cobertura de distintas siglas u organizaciones.

La confusión ya se hizo evidente e intencionada en la primavera de 1936, en la estrategia catastrofista que los dos principales líderes de las derechas derrotadas en las elecciones - Gil Robles y Calvo Sotelo-, pusieron en práctica en el Parlamento ${ }^{4}$. Y ha continuado hasta nuestros días pese a que gracias a los trabajos que en los últimos años se han publicado conocemos mejor la identidad partidista o sindical de las víctimas de esta violencia, la evolución cronológica de los incidentes o los actores principales que participan en estos conflictos. Y así sabemos, por ejemplo, que la mayor parte de la víctimas producidas en el mundo rural eran campesinos, jornaleros o huelguistas que murieron o resultaron heridos a manos de las fuerzas de orden público, principalmente Guardia Civil, mientras que en la violencia urbana de estos meses frentepopulistas los actores principales fueron pistoleros, tanto de la izquierda política y sindical, como de las organizaciones de la extrema derecha, falangistas y carlistas principalmente ${ }^{5}$.

Esta versión manipulada de los conflictos de orden público hecha por los portavoces de las derechas, en la que se mezclaban actos de violencia, delitos comunes o conflictos laborales, no pasó desapercibida para un testigo presencial de la época, Claude G. Bowers, el embajador norteamericano en Madrid entre 1933 y 1939. Como escribiría posteriormente este diplomático en su libro de memorias, los incidentes que se producían en los más variopintos luga-

${ }^{3}$ Su primer trabajo sobre este tema lo publicó en 1984 en un libro colectivo: Aróstegui, 1984, pp. 309-343. Diez años después, en 1994, coordinaría dos importantes volúmenes monográficos en sendas revistas: «La militarización de la política durante la II República», en Historia Contemporánea, 11, 1994, y «Violencia y política en España» en Ayer, 13, 1994. También, por citar los libros más relevantes de esta temática: Juliá (dir.), 2000; Cruz, 2006; Rey, 2008; González, 2015. Un análisis reciente de esta historiografía, en: González, 2017, especialmente las páginas 160-166.

${ }^{4}$ Sobre el papel que esta campaña de propaganda tuvo como complemento a los planes de los militares que preparaban el golpe del 18 de julio: Viñas, 2019, especialmente su capítulo 10, «Una estrategia sincronizada», pp. 193-206.

5 González, 2015, especialmente el capítulo 5, pp. 261-304. 
¿Violencia política o delincuencia común? Los sucesos de Jerez y Arcos de principios...

res eran «cuidadosa y sistemáticamente compuestos diariamente y publicados en los periódicos antidemocráticos» Y añadía con agudeza:

«La prensa extranjera daba la mayor importancia a esto. Era como si en los Estados Unidos, por ejemplo, todas las peleas, todas las muertes, todos los robos, crímenes, huelgas, no importa lo insignificante que fuesen, se anotaran y se publicaran en la primera página del The New York Times bajo el titular permanente: «Desórdenes sociales en los Estados Unidos» 6 .

Un ambiente de desorden y caos que ocho décadas después no dudan en rescatar Álvarez y Villa, con especial énfasis al narrar lo que ocurre entre el 17 y el 20 de febrero, es decir, en los cuatro días que siguen al de las votaciones, con el claro objetivo de cuestionar la legalidad y la legitimidad de la victoria del Frente Popular ${ }^{7}$.

\section{3. ¿Delitos sociales o delincuencia común? Sus orígenes}

En esta confusión interesada de incidentes de todo tipo, son catalogados como hechos de violencia política una serie de acciones protagonizadas por individuos armados, brumosamente relacionados con los medios anarquistas, que lejos de actuar con este tipo de intencionalidad las realizaron en calidad de pistoleros o delincuentes que habían hecho de sus actuaciones al margen de la ley su forma de vida habitual.

En la historiografía más reciente, creemos que ha sido Juan Cristóbal Marinello el autor que más y mejor ha profundizado en esta cuestión de definir los perfiles de la delincuencia político-social durante los años de la Restauración y de la Segunda República, intentando delimitar qué se entendían por «delitos políticos» y en qué se diferenciaban de los llamados «delitos sociales» ${ }^{8}$. En el periodo republicano, particularmente, al calor de las intervenciones que se produjeron en la discusión de la Ley de Orden Público, aprobada en julio de 1933 y que provocó la derogación de la

${ }^{6}$ Bowers, 1977, p. 206.

7 Álvarez y Villa, 2017, capítulo séptimo que titulan «Cuatro días decisivos», pp. 275 403. Los planteamientos de este libro han sido cuestionados en varias de las recensiones de las que ha sido objeto. La más reciente en: González y Sánchez, 2018, pp. 851-881.

8 Sobre el concepto de «delito social» y la dificultad para encontrarle una tipificación o definición legal clara en el código penal: Marinello, 2016, Los delitos... 
polémica Ley de Defensa de la República, en vigor desde dos años antes ${ }^{9}$. Sin embargo, consideramos que historiográficamente se le ha prestado poco interés al análisis de aquellas otras acciones que no se pueden considerar ni delitos políticos, ni delitos sociales porque se asemejan a lo que podríamos entender como delitos comunes, totalmente descontextualizados de cualquier conflicto político o laboral y violentando el código penal entonces vigente, ya fuera robando para subsistir, mediante la fórmula del atraco, agrediendo a otras personas, conocidas o desconocidas o atentando contra agentes de la autoridad por una venganza personal o de otro tipo ${ }^{10}$.

La presencia de delincuentes en los grupos armados que se movían en los medios anarquistas era algo que ya se venía produciendo desde principios de los años veinte al calor de los enfrentamientos violentos que protagonizaron en Cataluña estos grupos cercanos a las organizaciones obreras con los pistoleros protegidos y pagados por las entidades patronales y, en algunos momentos, por las propias autoridades gubernamentales. Lo cuenta Chris Ealham en el relato que hace de la Barcelona de este periodo. Describe cómo los que se llamaban «grupos de afinidad» o «grupos de acción» no sólo estaban para proporcionar guardaespaldas a los más destacados líderes obreros, sino que también organizaban «colectas armadas» [sic] para los sindicatos en los lugares de trabajo y en las calles y cómo se autofinanciaban mediante «expropiaciones» - así está traducido- para garantizar su autonomía ${ }^{11}$.

Una realidad que, ya entonces, era vista con más sentido crítico por Ángel Pestaña, uno de los principales dirigentes de la CNT, a tenor de lo que contaría en sus memorias. Escribía:

«Entre la avalancha de trabajadores de buena voluntad que acudían a los Sindicatos, venía también esa clase especial de individuos que viven en el lindero incierto que hay entre el trabajo y la delincuencia común. Individuos que un día trabajan, y al día siguiente, si la ocasión se les presenta, roban o matan, que para ellos, al fin y al cabo, todo es igual» ${ }^{12}$.

${ }^{9}$ Marinello, 2016, Las izquierdas.... Consulta realizada el 10 de mayo de 2019.

${ }^{10}$ Escribe Marinello en Los delitos..., que lo que parece quedar claro cuando se analiza la tipificación que se le quiere dar a los llamados «delitos sociales» es que siempre estaban relacionados con una lucha sindical o laboral, pp. 544-545.

11 Ealham, 2005, pp. 98-99. Pone como ejemplo más paradigmático de estos grupos a «Los Solidarios» en el que estaban Durruti, los hermanos Ascaso o Juan García Oliver, por citar algunos de sus miembros, protagonistas, según escribe, de «algunas de las expropiaciones y asesinatos más impresionantes de la época».

12 Pestaña, 1974, pp. 174-175. 
¿Violencia política o delincuencia común? Los sucesos de Jerez y Arcos de principios...

Este panorama era corroborado por otro destacado dirigente cenetista, Adolfo Bueso, al describir el atentado que se preparó contra el general Martínez Anido el 23 de octubre de 1922 y comentar quiénes fueron sus autores. De uno de ellos - que se llamaba Bermejo - y que moriría en la intentona, narraba que lo había conocido en Valencia, donde «se ganaba la vida robando lo que podía», aunque él mismo decía que en el fondo «era anarquista» ${ }^{13}$. Y, más adelante, en el balance que hacía de esta violencia, no dudaban en escribir que «los pistoleros, que habían empezado por actuar exclusivamente para la organización o los grupos, pronto conceptuaron que una buena parte del botín les correspondía, ya que se jugaban la vida, y vino lo de entregar una cantidad y quedarse con el resto». Y terminaba:

«Luego, ya, ni eso. Los atracadores se convirtieron en gángsters y obraban por cuenta y provecho propio, sin perjuicio, si caían presos, de reclamar el auxilio de los Comités Pro-Presos» ${ }^{14}$.

Hasta que llegó la Dictadura de Primo de Rivera a mediados de septiembre de 1923. Incapaces de soportar la represión que se abatió contra ellos, estos grupos desaparecieron rápidamente y sus miembros más conocidos no tardaron en abandonar el país para seguir viviendo al margen de la ley allí por donde pasaban o implicándose en alguna que otra conspiración que se preparó contra el régimen primorriverista, que terminaría fracasando.

\section{El retorno del pistolerismo en la Segunda República}

Después de su práctica desaparición como organización en los años de la Dictadura, con la llegaba de la Segunda República la CNT volvía a la legalidad y celebraba su tercer congreso a mediados de junio de 1931 .

13 Bueso, 1976, volumen I. Se cuenta en las pp. 173-175.

14 Ibídem., p. 261. Esto mismo es lo que reconocía otro destacado militante cenetista de estos años, Joan Ferrer, en: Porcel, 1978. Después de afirmar que, «asaltar un banco era un episodio de guerra social», no dudaba en reconocer que, «hubo individuos de los que se dedicaron a este trabajo que, faltos de una moral y una ideología, sintieron nacer la torva ambición individual y, dejando de actuar para la comunidad, pasaron al robo, a robar para lucrarse ellos» (p. 120). Las memorias de uno de estos personajes, que incluye sus andanzas y robos en la zona republicana de la guerra civil: Mir, 2009, especialmente las páginas 27-63. Herrerín, 2019, también recoge esta relación entre anarquistas y atracadores, vid. pp. 233-234. 
En el mismo, se recuperaban las estructuras clandestinas de años anteriores con la creación de una llamada Secretaría de Defensa y la formación de los ahora llamados «comités de defensa» como su brazo operativo, herederos de los «grupos de afinidad» y de «acción» que existieron diez años antes ${ }^{15}$. Unas estructuras «alegales» que quedaron más o menos relacionadas con los grupos «faístas» que no tardaron en desplegarse por toda la geografía peninsular. De este modo, por ejemplo, la Regional andaluza de la CNT no tardaría en aprobar un llamado «Plan de actividades revolucionarias», descargando la tarea de avanzar hacia la «Revolución Social» en los llamados Grupos o Cuadros de Defensa que se deberían crear «en todas las poblaciones y por todos los sindicatos» para realizar cuantos trabajos fueran necesario hasta alcanzar el «hecho subversivo» ${ }^{16}$. Y es que pronto quedó en evidencia que había un sector destacado del movimiento anarquista español que estaba dispuesto a combatir a la República desde el primer momento, mediante acciones de lo que se llamó la «gimnasia revolucionaria», provocando una espiral represiva que radicalizaría a los trabajadores y que debía llevar - según ellos - a un enfrentamiento final con las estructuras del Estado hasta propiciar su hundimiento y el triunfo del «comunismo libertario» ${ }^{17}$.

Y con la reconstrucción de los grupos armados que ya habían existido en los años veinte y la formación de otros nuevos, como ocurrió en Andalucía, volvieron otra vez los pistoleros y sus actividades al margen de la ley. Una circunstancia que se vio favorecida por el control que a partir de principios de 1932 ejercieron los sectores más radicales del anarquismo sobre

15 Alcalde, 2013, pp. 59-60.

16 Boletín de la CNT de España, número 2, noviembre de 1931. Actas del Congreso de la Regional Andaluza, p. 11.

17 Álvarez Chillida, 2011, p. 55. Uno de los líderes de este sector más radical del anarquismo, Juan García Oliver también cuenta cómo se produce esta reorganización de la CNT en las primeras semanas de la República: «Paralelamente a la creación de sindicatos, grupos de afinidad ideológica, ateneos, la juventud obrera debería ser agrupada en formaciones paramilitares de núcleos reducidos sin conexión entre sí, pero estrechamente ligados a los comités de defensa de barriadas», en: García Oliver, 1978, p. 115. Y dos páginas más adelante cuenta un primer tiroteo que se produce el Primero de Mayo de 1931 en la Ciudad Condal, «entre los guardias y los compañeritos que llevaban sus pistolas «por lo que pudiera ocurrir», ibidem., p. 117. Sobre la evolución del anarcosindicalismo en estos años de la Segunda República y sus problemas internos entre «treintistas» y «faístas», sigue siendo fundamental: Casanova, 1997. Y sobre el concepto de «gimnasia revolucionaria» y la estructura interna que debían tener estos Comités de Defensa, según una ponencia que se aprobaría en 1934, vid. Fontecha, 1994, pp. 153-179. 
¿Violencia política o delincuencia común? Los sucesos de Jerez y Arcos de principios...

los órganos de dirección de la CNT, expulsando a los «treintistas» más moderados y abriendo un ciclo insurreccional que se plasmó en la convocatoria de tres huelgas generales revolucionarias, en enero de 1932 y 1933 y en diciembre de este último año, después de la derrota electoral de las izquierdas frente a la CEDA y el Partido Radical. Las tres fracasaron, pero provocaron un importante número de muertos, heridos y detenidos y una notable crisis financiera en los sindicatos, lo que favoreció la relación de dependencia de la central confederal con respecto a estas bandas ${ }^{18}$. Y es que el relevante número de encarcelados después de estos conflictos hizo que los comités propresos ya no pudieran cubrir sus gastos con las tradicionales funciones benéficas y colectas y que se vieran obligados a buscar «distintos mecanismos de financiación [sic]» ${ }^{19}$, como los atracos a los bancos o entidades financieras y los asaltos sobre los patronos cuando se sabía que tenían encima el dinero de las pagas a sus empleados.

Un testigo privilegiado de aquellos años porque ya residía en España, el hispanista Gerald Brenan, escribe que una de las razones que explicaría el acercamiento de delincuentes comunes a las filas del anarcosindicalismo fue el sentimiento de simpatía hacia todos los que emprendían el camino del delito «por haber sido maltratados o injuriados por la sociedad» ${ }^{20}$. Efectivamente, esta era una idea que había tenido un profundo arraigo en la ideología del anarquismo español ya desde finales del siglo XIX y principios del XX, como bien ha explicado José Álvarez Junco ${ }^{21}$.

Una línea argumental sobre las raíces de la delincuencia como producto de la injusticia social que reaparecía con toda su fuerza en la prensa anarquista de la Segunda República, ya fuera en las páginas de Solidaridad Obrera, ya en las de Tierra y Libertad. No lo podía decir más claro, por ejemplo, el diario cenetista catalán en un artículo que publicaba sin firma el 25 de enero de 1933 y que significativamente se titulaba «Atra$\cos \gg$ :

18 Sobre estas tres huelgas insurreccionales: Casanova, 1997; Villa, 2011; Herrerín, 2015.

19 La expresión «mecanismos de financiación» es de Ealham, que así llama a estas actividades delictivas en su libro, en el apartado que titula «Los expropiadores», pp. 231-238.

${ }^{20}$ Brenan, 1977, p. 310.

21 Véase, por ejemplo, el Almanaque de la Revista Blanca para el año 1904, citado en Álvarez Junco, 1991, 2. a edición, p. 267. De hecho, una de las figuras más destacadas de estos años, Anselmo Lorenzo llegó a escribir que, «el germen de todos o casi todos los delitos penados por el legislador» se hallaba «en la defectuosa organización de las sociedades», y se preguntaba a continuación: «¿no es la miseria la que más frecuentemente impulsa al crimen (...) y la actual forma de propiedad la «causa del asesinato y del robo?». 
«Ahora podemos y debemos renovar algunas consideraciones que en anteriores ocasiones hemos hecho. Volveremos a decir que de toda la delincuencia tiene la culpa la propia sociedad burguesa que, con sus privilegios para los unos y sus persecuciones y dificultades para otros, establece irritantes diferencias de posición material, de educación y de vida, que determina la delincuencia profesional y la ocasional $(\ldots) »^{22}$.

Pero al margen de esta justificación ideológica, hubo en estos años una segunda explicación, más sorprendente, para argumentar la presencia de delincuentes en las filas de las organizaciones anarcosindicalistas. La dio Eduardo Barriobero, jurista y diputado en las primeras Cortes republicanas cuando se discutió la Ley de Orden Público, que sería aprobada a mediados de 1933. Barriobero, que conocía bien los ambientes anarquistas porque había actuado algunas veces como abogado defensor de sus presos, en uno de los debates que provocó la discusión de esta ley, pretendía que se produjera la exclusión de algunos delitos de las competencias del Tribunal del Jurado. Después de reconocer que se estaba pasando por un periodo en el que los atracos y las colocaciones de bombas «se multiplicaban de un modo verdaderamente alarmante», consideraba que contra ellos había que tomar algún tipo de medida, pero no creía que el remedio estuviera en esta ley. Pensaba que en aquellos meses con tantos militantes de la CNT en las cárceles, «la delincuencia profesional» y «el ladrón de oficio» habían entrado en contacto con ellos y habían visto el apoyo que tenían estos sindicalistas presos porque le llevaban el jornal, les buscaban el abogado y «les prestaban calor de asistencia y de amistad» ${ }^{23}$. Pues bien, estos delincuentes presos, al ver esta realidad, sacaron la siguiente conclusión, según lo contaba en su intervención:

«(...) aquí está el remedio; nos hacemos sindicalistas». Y cuando han salido de allí han puesto todos los medios para obtener un carnet de la Confederación o de la F.A.I. y disfrazan sus debilidades con este carnet. Hay aproximadamente 500 bandidos, bandoleros, degenerados, delincuentes profesionales que llevan estos carnets. Y ¿por qué los llevan? Porque a la

22 Solidaridad Obrera (25 de marzo de 1933), p. 1. Más referencias sobre estos discursos en Ealham, 2005, pp. 248-249. Y más textos sobre esta justificación de la delincuencia común, en esta misma prensa, cuando después de las elecciones de 1936 se apruebe el decreto sobre la amnistía para los delitos políticos y sociales, excluyendo a los llamados delitos comunes.

${ }^{23}$ Diario de Sesiones del Congreso de los Diputados (Sesión del 7 de junio de 1933), p. 13383. Una biografía de este diputado en: Carretero, 2017. 
¿Violencia política o delincuencia común? Los sucesos de Jerez y Arcos de principios...

Policía, o no les conviene quitárselos (...), o no se atreven a quitárselos. Pero, conocerlos los conocen como los conozco yo (...). No quieren acabar con ellos. Les conviene que sobre ese medio se extienda una aureola de difamación y el procedimiento es éste (...). A estos (bandidos) se deben, en su mayoría, estos delitos, que ahora lamentamos todos» ${ }^{24}$.

Lo cierto es que ya en este primer bienio republicano hay numerosas pruebas de la actuación de estos individuos que pertenecían a los grupos armados cercanos al anarquismo. Son ellos los que unas veces participan en tiroteos y atentados contra otros rivales sindicales, como ocurría en Sevilla, o los que realizan otros atentados que se dan en la provincia de Cádiz, ya fuera en su capital o en Jerez ${ }^{25}$. Unas veces cumpliendo órdenes que les llegaban de los dirigentes de la sociedad obrera de turno por las motivaciones que fueran y en otras ocasiones lo hacían a su libre albedrío, por su cuenta y riesgo, buscando su beneficio particular. Un observador perspicaz como era el ya citado Gerald Brenan no dudó en recoger esta situación, cuando en su «laberinto» clásico escribió sobre la conducta de la CNT en el bienio reformista (1931-1933):

«Una particularidad del anarquismo español que se hace notar cada vez más a partir de ahora fue la admisión en sus filas de malhechores profesionales - ladrones y pistoleros que ciertamente no hubieran sido aceptados por ningún otro partido u organización de la clase trabajadora - , junto con idealistas de la más pura y desinteresada calidad» ${ }^{26}$.

Sin embargo, la represión que practicaron los gobiernos de la coalición radical-cedista durante 1934 y 1935 los dejó momentáneamente paralizados. Por este motivo, hubo que esperar a principios de 1936, después que el escándalo del «estraperlo» hundiera al Partido Radical, cuando ya con un nuevo Ejecutivo provisional encargado de convocar nuevas elecciones, volvieran a reaparecer estos grupos y sus acciones al margen de la ley. Fue lo que ocurrió en Jerez de la Frontera a mediados de enero.

${ }^{24}$ Ibídem.

25 Sobre los enfrentamientos armados entre pistoleros cercanos a la CNT y a los sindicatos vinculados al Partido Comunista en Sevilla, vid. Macarro, 1985, pp. 293-305. Sobre algunas de sus acciones en Cádiz, vid. Gutiérrez Molina, 1994, pp. 181-183. Y sobre los de Jerez, Caro, 2001, pp. 298-299.

${ }^{26}$ Brenan, 1978, p. 309. Sobre lo ocurrido en Cataluña y con un planteamiento parecido al nuestro han escrito Josep Pich, David Martínez y Xavier Casals en: «Els gángsters de la FAI. Justo Bueno Pérez», Afers, 89, 2018, pp. 135-164. 


\section{El atentado del día 17 en Jerez de la Frontera}

En una ciudad como Jerez de la Frontera, convertida en los años de la República en uno de los principales bastiones del anarquismo andaluz, no debía extrañar que las bombas y las pistolas hubieran estado presente en algunos de los principales conflictos que tuvieron lugar en la población, especialmente una vez abierto el ciclo insurreccional de principios de 1933, con la huelga general revolucionaria lanzada el 8 de enero, que no tardaría en fracasar ${ }^{27}$. Grupos de pistoleros llegaron a actuar en este y en otros movimientos huelguísticos o insurreccionales, unas veces asesinando a un sereno, como ocurrió en la misma noche de este citado día, otras atentando contra un grupo de esquiroles durante otro paro ilegal o bien atracando a un propietario que llevaba en su coche varias miles de pesetas para pagar a los trabajadores de su cortijo ${ }^{28}$.

Todavía habría más incidentes en los que participan estos «grupos de acción», pero el atentado que se produjo en las primeras horas de la noche del 17 de enero de 1936 supuso un claro salto cualitativo porque no se desarrolla en un contexto de conflictividad y tampoco tuvo una aparente motivación sindical o política.

Eran las siete cuando en un despacho de vinos situado en la plaza del Carbón, el jefe accidental de la Guardia Municipal, Manuel Aranda Aguilar, y el subjefe de la Guardia Rural, esperaban sentados en una mesa la llegada del guardia civil José García Vera para hablar sobre las gestiones que se estaban realizando en torno a un robo cometido en Cádiz y que había provocado que se desplazara a Jerez el comisario de Vigilancia de la capital, con varios agentes a sus órdenes.

Apenas había traspasado la puerta del establecimiento el guardia civil cuando se oyó una descarga cerrada de disparos. A consecuencia de los mismos, resultaba herido de muerte un obrero tonelero de 60 años, que se encontraba tranquilamente sentado junto a la puerta y también era lesionado de gravedad el citado guardia, que parecía el objetivo de los tiros, con cinco heridas de bala en distintas partes de su cuerpo. Asimismo,

27 La CNT venía siendo desde su fundación la fuerza sindical hegemónica en el movimiento obrero jerezano. En 1932 sus entidades agrupaban a 9.952 trabajadores de la ciudad, mientras que las de la UGT tenían 3.574 y los de las sociedades autónomas eran 1.250. Y en Arcos de la Frontera ocurría lo mismo. Vid. Caro, 2001, pp. 108-109, y Temblador, 2019.

${ }^{28}$ Caro, 2001. Se cuentan estos hechos especialmente en las pp. 254-298. 
¿Violencia política o delincuencia común? Los sucesos de Jerez y Arcos de principios...

el jefe accidental de la Guardia Municipal recibía un disparo en el brazo derecho, una herida calificada de «grave» por los facultativos que lo atendieron poco después en la cercana Casa de Socorro $^{29}$.

Aunque en aquel momento, por lo inesperado y la rapidez con la que se produjo el ataque, no fue posible identificar inmediatamente a los autores del mismo, esto sí se logró al día siguiente cuando fueron localizados y abatidos en un tiroteo producido en las primeras horas de la mañana en la vecina población de Arcos de la Frontera. Se trataba de tres individuos que se movían cerca de los círculos anarquistas locales y que probablemente formaban parte de uno de los «grupos de acción» que venían actuando por la zona desde meses atrás. Sorprendía, en primer lugar, la juventud de los mismos. Se llamaban Antonio Franco Orellana, apodado «El Churriana», que sólo tenía 18 años, Julio Jiménez Correa, alias «El Chupi», de 20 años y Juan Domínguez Bustillo, apodado indistintamente «El Raspadura», «El Raspador» o «El Raspao» en los documentos judiciales y que fue el único que sobrevivió, aunque herido y detenido ${ }^{30}$.

En segundo lugar, también era llamativo como señala Jesús Núñez, el salto cualitativo que suponía esta agresión, la primera que se realizaba en la provincia de Cádiz de forma directa contra un miembro de la Benemérita, sin que hubiera un conflicto político o laboral de por medio como hasta entonces había ocurrido ${ }^{31}$. Y en tercer lugar, conmovió la brutalidad del atentado, hecho con disparos indiscriminados que provocaron la muerte inmediata de un obrero tonelero muy apreciado en su sindicato $^{32}$.

${ }^{29}$ El relato de los hechos se ha basado en lo que publicaron al día siguiente los dos diarios derechistas locales, El Guadalete y el Diario de Jerez. También en el informe que la Policía Municipal envía al alcalde de la ciudad el día 18, recogido en: Archivo Municipal de Jerez de la Frontera. Protocolos. 1936. Tomo 613.

${ }^{30}$ La identificación de los asaltantes procede del expediente judicial del tercero de ellos. Archivo del Tribunal Militar Territorial Número 2(en adelante ATMT2). Sevilla. Legajo 115, Expediente 3483, Causa n. ${ }^{\circ}$ 12, Año 1936

31 Núñez, 2016, p. 173.

32 Inmediatamente después de la muerte de este tonelero, la sociedad obrera a la que pertenecía, vinculada históricamente a la UGT, abrió en las páginas de su periódico una suscripción para ayudar a la familia del fallecido que un mes después de que ocurriera el óbito ya había alcanzado la cifra de 836,60 pesetas. Vid. El Martillo (21 de febrero de 1936), p. 2. Precisamente en este órgano de prensa de los toneleros jerezanos, el 23 de junio de 1933 , se publicaba un poema titulado «El pistolero» en el que se denunciaba abiertamente el turbio origen que tenían estos individuos y los oscuros intereses que les mo- 
Aunque la prensa, al narrar los hechos, los relacionó con la investigación del robo producido en Cádiz varios días antes, cuando el pistolero herido y detenido en Arcos prestó su primera declaración ante el juez de instrucción dijo que se había tratado de una venganza contra el guardia civil, que había premeditado en la cárcel - de la que había salido dos semanas antes - «por haberlo detenido en distintas ocasiones» $^{33}$.

Según contó también, los tres se habían reunido aquella mañana y después de repartirse las pistolas, protagonizaron una primera agresión cuando se encontraron con dos jóvenes que les parecieron «fascistas». Los llegaron a cachear, sin encontrarles armas y antes de que les permitie-

vían, más de mercenarios que de sindicalistas. Decía el poema, que firmaba Gabriel Enciso Núñez:

«Es negro el corazón del pistolero.

De la charca social salió al camino

$\mathrm{y}$, de sus propios vicios, prisionero,

los vicios le marcaron el destino.

¿Es español? Su tipo es de extranjero,

¿De qué pueblo o de qué caverna vino?

No tiene hogar, ni patria; aventurero

cruza el mundo del crimen peregrino.

Se vende - es negra y vil la mercancía,

Pero es más vil, más bajo todavía,

quien le busca, le compra y le contrata

le habla de la República española

con despecho, le entrega una pistola

le da dos duros y le dice ¡Mata!»

33 En Cádiz, se había producido un intento de robo en la fábrica de cervezas «La Gaditana» el 10 de enero, que fue abortado por la Policía, con el saldo de un asaltante muerto y otro herido. Vid. Gutiérrez Molina, op. cit., p. 183. Juan Domínguez Bustillo se declaró autor de los disparos hechos sobre el guardia y también dijo que había estado detenido por «incendiario y tenencia de explosivos» y según el sumario que se le abrió, estaba en libertad provisional procesado por un juzgado de Jerez por «el delito de incendio». ATMT2, f. 3v. Más tarde en otra declaración, consciente de la responsabilidad que había contraído en esta primera declaración hizo otra en la que se desvinculaba completamente de los hechos y responsabilizaba de los mismos a uno de los muertos. Contaba lo siguiente: «el Churriana y el Julio propusieron cometer un atestado [sic] contra el Guardia civil apellidado Vera, porque decían que era un individuo que cuando cogía a uno lo maltrataba, a lo que el dicente se negó, pues a él cuando le detenía no le hacía nada; que al pasar los tres por el tabanco de vinos conocido por el de Manolete, vieron que allí se encontraba el Guardia Civil, Vera, y entonces el declarante dijo «yo me voy», recogiéndole el Churriana la pistola del 7,65 que por la mañana le habían entregado y cometieron el atentado no sabe si desde la puerta o entraron en el tabanco». ATMT2, f. 34 y $34 \mathrm{v}$. 
ran salir corriendo, el llamado «El Churriana» le dio a uno un golpe en la cabeza con la pistola del nueve largo ${ }^{34}$. Pues bien, pese a que los indicios apuntaban a una acción arbitraria de estos tres individuos sin más explicación que una venganza particular o personal de uno de ellos, y que a los pocos días se hizo pública la declaración del superviviente en la que confesaba nítidamente el móvil del atentado, lo cierto es que este suceso, en el periodo preelectoral en el que se encontraba el país, no tardó en ser revestido de intencionalidad política por la prensa derechista local ${ }^{35}$. Pese a que todo señalaba, como se vería en el sumario, a la vinculación de estos pistoleros con los medios anarquistas, para El Guadalete, el diario que era propiedad del conde de los Andes, la culpa la tenía la Internacional Comunista, y así lo contaba en el editorial que publicaba al día siguiente de los hechos:

«Declarado el periodo electoral, las escenas execrables del pistolerismo se han recrudecido. Dense cuenta de ellos los obreros honrados. Observen que ellos tampoco escapan de las iras de los malhechores. Son instrucciones del Komintern ruso. Los malvados las cumplen. Hay dinero ruso. Es público» ${ }^{36}$.

Más descaro tenía Diario de Jerez, controlado por los carlistas. El titular con el que abría la información de la agresión no podía ser más contundente: «Las izquierdas comienzan su campaña electoral» ${ }^{37}$. Y ya en el interior de la información, antes de contar lo sucedido, escribía:

«Ante episodios como el de anoche en nuestra ciudad, el pueblo entero debe reaccionar virilmente. Próximas están las elecciones generales. Lo de anoche es un acto de terror y anticipo de la política, que de triunfar, seguiría el conglomerado izquierdista. Tenemos el ejemplo del primer bienio de la República (...) y miles víctimas inocentes caídas bajo el imperio del terror y la indefensión de los Gobiernos irresponsa-

${ }^{34} \mathrm{El}$ incidente se cuenta en el sumario y también lo recogió la prensa.

35 La publicación de que la causa del atentado es la venganza, según la declaración del propio Domínguez Bustillo en: ABC (28 de enero de 1936), p. 29.

${ }^{36}$ El Guadalete (18 de enero de 1936), p. 1. Francisco Moreno Zulueta, conde de los Andes, era un destacado propietario y el político más importante de la comarca jerezana durante la monarquía de Alfonso XIII. Con la llegada de la República se exilió a Francia, desde donde jugará un importante papel en la conspiración que los monárquicos alfonsinos prepararon contra el régimen republicano. Se narra en: Viñas, 2019, pp. 56-70.

37 Diario de Jerez (18 de enero 1936), p. 1. 
bles y su cortejo de socialistas, masones y separatistas, que ampararon la impunidad de criminales y pistoleros» ${ }^{38}$.

Pero lo peor todavía no había llegado. Ocurría en Arcos el día siguiente, cuando los lectores de estos periódicos estaban conociendo los hechos producidos la noche anterior.

\section{El tiroteo de Arcos de la Frontera}

Era la mañana del 18 de enero cuando cerca de la escuela de niñas de la calle Joya dirigida por la maestra Doña Vicenta se oían varias detonaciones, por lo que ésta inmediatamente ordenaba a sus alumnas que se refugiaran bajo sus pupitres. Dos calles más abajo la conocida popularmente como «Taberna Garrido», en el barrio de San Francisco, estaba siendo escenario de un suceso que ocuparía una gran parte de los periódicos nacionales en los días siguientes. Sobre las diez y media varios vecinos jugaban a las cartas en una tienda de bebidas en la calle Romero Gago, cuando entraban tres jóvenes que dando palmas solicitaban cinco botellas de cerveza. Eran Antonio Franco «El Churriana», Juan Domínguez «El Raspador» y Julio Jiménez «El Chupi», autores del atentado de la tarde-noche del día anterior en Jerez.

Mientras los tres sospechosos comían latas de conservas, chorizo y pan que compraban en un establecimiento cercano, las fuerzas del orden público realizaban las comprobaciones propias del dispositivo de vigilancia activado en la zona por las trágicas noticias procedentes desde Jerez. El alcalde de Arcos, Andrés Escot, teniendo constancia de que sobre las nueve de la mañana tres sujetos desconocidos con características similares a los autores del atentado anterior, habían entrado en la población, enviaba a dos guardias municipales a inspeccionar los establecimientos de la ciudad. Localizados los tres pistoleros, no tardaban en telefonear al cuartel de la Guardia Civil, que mandaba una pareja a la zona del tabanco. Con la pretensión de detenerlos, el alférez José Díaz vestido de paisano y revólver en mano entró en el local, junto con los dos guardias civiles y un guardia municipal, dando la voz de «manos arriba». Sin embargo, los fugitivos viéndose acorralados empezaron a disparar, produciéndose un tiroteo que acababa con la vida de dos de ellos y la del alférez - al abalan-

\footnotetext{
38 Ibídem.
} 
¿Violencia política o delincuencia común? Los sucesos de Jerez y Arcos de principios...

zarse sobre «El Raspador» y recibir dos disparos de éste - mientras que el guardia Antonio Campanario resultaba herido en la mano izquierda.

Sobrevivía a la refriega uno de los pistoleros, Juan Domínguez, que con dos heridas, una en el pecho y otra en la cara, además de algunos rasguños, permaneció tumbado, haciéndose el muerto, al tiempo que se producía la descarga de los fusiles de los guardias civiles ${ }^{39}$.

La luctuosa noticia no sólo causó un hondo pesar en el pueblo de Arcos sino también en todo el país y obligó al presidente del Gobierno a hacer una declaración pública de apoyo a la Guardia Civil al día siguiente, que sería inmediatamente recogida en todos los diarios nacionales 40 .

Procedentes de Cádiz y otros lugares llegaron a la ciudad todo un elenco de autoridades civiles y militares, entre las que estaban conocidos políticos y exdiputados derechistas, como Carranza y García Atance, el gobernador civil de la provincia Luis Armiñán o el coronel de la Guardia Civil de Málaga, Fulgencio Gómez. Fue el gobernador civil quien, por mandato del propio presidente del Consejo de Ministros, presidió el funeral y el que colocó la Cruz de Caballero de la Orden de la República al cadáver del oficial de la Benemérita. El entierro de Díaz constituyó una manifestación multitudinaria de duelo y de repulsa a este tipo de actos, finalizando con unas descargas por parte de los guardias y con vivas a la República, a la Guardia Civil y a España ${ }^{41}$. En honor al alférez, el Pleno Municipal decidió cambiar el nombre de la calle «Salida a Jerez» por el de «Alférez Díaz», y el Ayuntamiento se hizo cargo de todos los gastos del funeral concediéndosele un nicho a perpetuidad en el cementerio municipal, todavía hoy intacto ${ }^{42}$.

39 Esta reconstrucción de los hechos está basada en los testimonios de los testigos y participantes en el tiroteo así como en la sentencia que dicta el tribunal encargado de juzgar al superviviente. En: ATMT2, Leg. 115, n. ${ }^{\circ} 3483$. El testimonio de la escuela procede de la entonces alumna Antonia Rodríguez Oca, de 93 años de edad, entrevistada el día 3 de agosto de 2015.

40 Rivas, 1976, p. 46. Por ejemplo, Ahora (19 de enero de 1936), p. 1. Y es que estos sucesos de Jerez y Arcos, por el número de víctimas, fueron los más sangrientos que se produjeron en toda España en el mes de enero de 1936. Entre otras cosas, dijo: «La Guardia Civil ha sido objeto de agresión en estos días. El Gobierno se asocia íntimamente al duelo del Benemérito Instituto y al de los familiares que cayeron en defensa de la sociedad y de la Patria. Parece que las dificultades que pone la ley electoral para la aplicación de sanciones gubernativas alienta a los criminales para lanzarse a la calle y actuar sueltamente (...) Todo aquel que se resista a la voz de alto puede sufrir consecuencias desagradables».

${ }_{41}$ El Guadalete (21 de enero de 1936), p. 1.; La Libertad (19 de enero de 1936), pp. 1-2.

42 Archivo Histórico Municipal de Arcos de la Frontera (en adelante AHMAF), Legajo 122, Actas Capitulares, sesión 7 de febrero de 1936, pp. 137-139. 
A pesar de que el discurso legitimador de los golpistas de 1936 asoció este suceso a los anarquistas locales en una estadística elaborada dos años después para conocer los desmanes y asesinatos de la «actuación marxista en España», no hay más que prestar atención a otras fuentes para constatar la fragilidad de este argumento, claramente interesado. Las informaciones que ofrece la prensa derechista tras el atentado son bastantes clarificadoras y contundentes, y ya nos aportan algunas pistas:

«El obrero de Arcos (...) lamenta como el que más el triste espectáculo que hoy han visto los arcenses, y de todos los labios han salido palabras contra los agresores (...) ¡Cuántos y cuántos obreros de la población y del campo, vimos! (...). El obrero arcense es digno, es honrado, y es incapaz de cometer actos como el que ha dado lugar a esta desgracia.

El paso que has dado hoy, obrero arcense, te ha valido mucho, y esa honradez tuya la han visto las dignas autoridades y tantos forasteros como han venido para unirse a tu duelo y has dejado bien sentada la fama de la que gozas» ${ }^{43}$.

Un testimonio que también repetía alcalde radical en el telegrama que remitía a El Guadalete y que, entre otras cosas, decía:

«(...) pueblo entero hállase consternado y comisiones de obreros testimonian sentimiento deseando se logre la reacción ciudadana y se eviten hechos anárquicos.

Quien proteja, ampare o disculpe los criminales hechos como el que nos conturba, ni es republicano, ni es español, ni es hombre, porque sería como dejar paso a la bestia humana y prescindir de la razón y la ley, y la razón y la ley son para mí las bases del régimen» ${ }^{44}$.

43 El Guadalete (21 de enero de 1936), p. 1.; El Bien Público (21 de enero de 1936), p. 3. Sobre la participación multitudinaria en los actos de despedida al alférez existen fotografías que pueden consultarse en PÉREZ, 2002, Vol. IV, p. 298. La lectura morbosa de la violencia fue aportada por Mundo Gráfico (29 de enero de 1936, p. 27) con la reproducción de fotografías con los cuerpos inertes de los dos pistoleros muertos, el relato de los testigos y los restos de sangre en el suelo. Por su parte, $A B C$ (23 de enero de 1936, p. 27) incluiría cinco ilustraciones gráficas: dos de los guardias Díaz y Antonio Campanario, una más del respaldo multitudinario al entierro del primero, así como otras dos de la recreación de los sucesos con un testigo y dos niños.

${ }^{44}$ El Guadalete (21 de enero de 1936), p. 1. 
A excepción de un artículo titulado «A quien a hierro mata, a hierro muere», publicado en Solidaridad Obrera, que con tono irónico mostraba cierta complacencia con la muerte del alférez, enviado desde Palamós por alguien que parecía tener cuentas pendientes con él, la prensa libertaria no llegó a reivindicar ni el componente político ni social del atentado, como tampoco llegó a publicar ninguna nota necrológica por la muerte de éstos que aparentemente eran sus «compañeros» de sindicato ${ }^{45}$. Incluso en las memorias del que fue secretario de la CNT-AIT de Arcos en la primavera de 1936 se señala que no había ninguna relación entre los pistoleros jerezanos y los círculos anarquistas arcenses. Sin embargo, el documento más concluyente en este sentido era el escrito que el propio sindicato anarcosindicalista local enviaba al alcalde arcense, reproducido en la prensa derechista en los días siguientes y que se conserva en el Archivo Municipal de la ciudad. En el oficio de «Fraternidad Obrera CNT-AIT», que representaba a cerca de cuatro mil obreros locales, además de informar que se suspendía la asamblea convocada para el día 25 de enero, «en señal de duelo por el infortunado alférez de la Guardia Civil», se señalaba que fue «asesinado bárbaramente en el cumplimiento de su dever [sic] ${ }^{46}$. Testimonio que no deja lugar a dudas del parecer del sindicato campesino libertario. Este episodio sangriento pasó a la historia más conocida de la ciudad y una estrofa que se cantó en los carnavales de 1936 todavía hoy se recuerda por algunos vecinos. ${ }^{47}$

${ }^{45}$ La cobertura informativa de los atentados de Jerez y Arcos en la prensa libertaria: Solidaridad Obrera (19 de enero de 1936), p. 5. Según escribe el anarquista Manuel Temblador en sus memorias, el artículo titulado «A quien a hierro mata, a hierro muere» fue escrito por Federica Montseny y publicado en El Luchador y en él se recordaba la conducta represora de Díaz contra los obreros cuando estuvo destinado en Cataluña. En: Temblador, 2019, p. 88. Nosotros hemos encontrado el texto firmado con las iniciales E.C.E. en Solidaridad Obrera (21 de enero de 1936), p. 6.

${ }^{46}$ La estadística en: AHMAF, n. ${ }^{\circ}$ 511, Expediente Administración municipal desde 18 de julio de 1936. El oficio de la CNT-AIT de Arcos en: AHMAF, Leg. 51, expediente 2. Fraternidad Obrera. Y el testimonio de Temblador sobre el atentado en: Temblador, 1980, p. 72.

47 Decía la copla:

«En el pueblo de Jerez en la Plaza del Carbón, fue tan grande el tiroteo, que un obrero falleció, un obrero falleció

(...)

Y el jefe de policía estaba en el hospital curándose las heridas (...) 


\title{
7. La detención y el proceso al superviviente
}

Detenido pues tras el tiroteo en Arcos, a Juan Domínguez se le abrió un primer proceso por el delito de asesinato y lesiones que terminó desembocando en otro por el de agresión a la fuerza armada, tramitado por la jurisdicción militar. Aunque inicialmente la apertura del proceso judicial se hizo en el juzgado de instrucción de esta población serrana, éste no tardó en remitirlo a su homónimo de Jerez, que era el que abrió la causa por el primer atentado de la noche del 17 de enero.

Esta instrucción judicial dio lugar a dos voluminosos expedientes con una completa documentación que va a poner de manifiesto varios aspectos relevantes del modo de vida y la actuación que hasta entonces venía desarrollando este grupo de personas que se movía entre la clandestinidad y la delincuencia ${ }^{48}$. En primer lugar, sobre el tipo de vida que llevaban. En la tarde del mismo día 18 en el que dos de ellos eran abatidos en Arcos, se presentaba ante el juez de instrucción que estaba empezando la causa una señora procedente de Jerez, de 44 años de edad. Decía que lo hacía porque al enterarse de lo que había ocurrido la noche antes en la ciudad donde vivía, tenía «la incertidumbre de que uno de ellos fuera su hijo» ${ }^{49}$. Personada en el cementerio, reconoció como tal a uno de los muertos, del que afirmaba que tenía 18 años y era el apodado «El Churriana». A continuación, declaraba que éste se había ausentado del domicilio familiar desde mediados del año anterior, salvo una tarde del mes de octubre, cuando volvió para comer y desaparecer de nuevo otra vez. Desde entonces, su

\author{
Cuando llegaron a Arcos \\ a la taberna Garrío [sic] \\ se hartaron de cerveza \\ y pintaron el desavío \\ Lo más malo que hicieron \\ cuando la guardia llegó \\ fue sacar el arma y disparar \\ contra el teniente [Díaz \\ que había mandado] Escot»
}

Cantada por Antonio Rosado Peña, de 74 años de edad, el 13 de junio de 2019.

48 ATMT2. Sumario Juan Domínguez Bustillo por el delito de agresión a la fuerza armada, legajo 115, documento n. ${ }^{\circ} 3483$, y Causa instruida al paisano Juan Domínguez Bustillo por el delito de agresión a fuerza armada, legajo 124, documento n. ${ }^{\circ} 4122$.

49 Ibidem., Leg. 115, documento n. ${ }^{\circ} 3484$, p. 37. 
madre decía que no lo había vuelto a ver, «no sabiendo nada de su vida, ni a lo que se dedicaba», ni tampoco si estaba afiliado a algún partido.

Para reconocer al otro delincuente fallecido no compareció nadie. Eso sí, como se les encontraron en los bolsillos la significativa cantidad de 322 pesetas, Juan Domínguez declaró que él y sus dos compañeros estaban afiliados a «la CNT de Jerez» y que este dinero procedía del atraco que los dos muertos habían cometido «por la parte de Algeciras» cuando él estaba en la cárcel, por lo que ignoraba también la procedencia de las tres pistolas intervenidas ${ }^{50}$.

La vinculación del superviviente con los círculos anarquistas jerezanos que él no había ocultado quedó todavía más en evidencia a raíz del informe que el Jefe de Vigilancia de la Comisaría de Jerez enviaba el 2 de febrero de 1936 al juez de instrucción que llevaba en caso. El retrato que hacía de este personaje no podía ser más expresivo. Antes de contar su detención el 18 de septiembre de 1934, por ser «un elemento perturbador» en la huelga general que los trabajadores del vino mantenían en las viñas y las bodegas y decir que también estaba incurso en un sumario del año 1933, lo retrataba de la siguiente manera:

«JUAN DOMINGUEZ BUSTILLO, es persona de pésimos antecedentes. Formaba parte de las Juventudes Libertarias de acción, afectas a la F.A.I. y que subvencionadas por distintos comités, encubiertamente tienen por lema mantener el estado alarmista en las poblaciones, no sin que por ello dejen de efectuar todo género de atentados a quienes estorban su labor. Sus amistades fueron siempre las de sujetos de ideas afines manteniendo relaciones directas con organizaciones afectas a la C.N.T.» ${ }^{51}$

Y que era el que ejercía como líder del grupo, a pesar de las reiteradas declaraciones exculpatorias que realizaba a lo largo de toda la instrucción judicial, lo ponía en evidencia el testimonio que uno de los agredidos en Jerez en la mañana del día 17 prestó ante la autoridad judicial el 24 de enero, al narrar los hechos. Además de denunciar a los tres pistoleros por sus apodos - los llamó «el Raspaó, el Chupi y el Churriana»-, acusaba al primero de los tres no sólo de haberle agredido, dándole «unos puñetazos», sino también de haber ordenado a los otros dos que no dispararan porque «era el jefe de ellos» ${ }^{52}$.

\footnotetext{
50 Ibidem., p. 34v.

51 ATMT2, Leg. 124, Documento n. . 4122, p. 61.

52 Ibidem., pp. 42 y $42 \mathrm{v}$.
} 
Cabecilla o no de este grupo, por ser el único que sobrevivió a los tiroteos y por la gravedad de los hechos en los que había participado, Juan Domínguez quedaría al margen de la amnistía que siguió al triunfo del Frente Popular, un mes después de los hechos y, después de reiterados trámites judiciales, sería una víctima más de la represión fascista que siguió al golpe militar del 18 de julio.

\section{Sin perdón}

Como es sabido, la victoria de las izquierdas en las elecciones de 16 de febrero de 1936 provocó grandes manifestaciones de alegría en las calles y también algunos tumultos en las cárceles porque muchos presos esperaban beneficiarse de la amnistía o del indulto prometido reiteradamente en la campaña electoral. Ante este panorama y para que la situación no se desbordara, el nuevo gobierno que se hizo cargo del país, al dimitir Portela Valladares, elaboró rápidamente un decreto-ley y sin esperar a la constitución de las nuevas Cortes lo sometió a la aprobación de la Diputación Permanente, que no dudó en prestar su apoyo para evitar un hipotético deterioro del orden público. El decreto-ley del 21 de febrero era conscientemente vago para evitar debates y para que el Ejecutivo tuviera unas amplias facultades para desarrollarlo. Tenía un único artículo e incluía junto a los considerados «delitos políticos», los llamados «delitos sociales». Y como en la amnistía del abril de 1934, estos últimos se vinculaban fundamentalmente a las trasgresiones de la ley de huelgas recogiendo las infracciones cometidas por móviles sociales o durante éstas, así como otros tipos de conflictos laborales ${ }^{53}$. Pero este decreto no iba a incluir los llamados delitos comunes, en contra de lo que reclamaban los principales órganos del prensa del movimiento anarcosindicalista, especialmente el semanario Tierra y Libertad, que no dudaba en considerar a esta clase de presos como «víctimas indefensas del orden social en que vivimos», mientras que, por el contrario, estaban li-

53 Decía el único artículo del decreto aprobado, pendiente de su ratificación como ley: «Se concede amnistía a los penados y encausados por delitos políticos y sociales. Se incluye en esta amnistía a los concejales de los Ayuntamientos del País Vasco condenados por sentencia firme. El Gobierno dará cuenta a las Cortes del uso de la presente autorización». Gaceta de Madrid del 22 de febrero de 1936, p. 1.515. 
¿Violencia política o delincuencia común? Los sucesos de Jerez y Arcos de principios...

bres en las calles «tantos delincuentes vulgares de la reacción política y de las finanzas» ${ }^{54}$.

Juan Domínguez, ya sometido a la jurisdicción militar, también quiso acogerse a los beneficios del decreto de amnistía por considerar «comprendido en ella el delito que se me acusa» ${ }^{55}$. Para esto contó con el apoyo del Comité Pro Presos de Jerez que denunció su caso en las páginas de Solidaridad Obrera protestando que alguien «hábil y sigilosamente ha amañado su proceso claramente social, transformándolo en delito común». Y añadía que «todo el pueblo de Jerez pide la amnistía para este preso, que es suyo» porque según este Comité:

«su caso es el de otros tantos revolucionarios, que acosados por la Guardia Civil y ante el temor de ser bárbaramente apaleados, se defienden como pueden. Sufre un tiroteo, y al final cae muerto un Guardia civil y nuestro camarada herido. Es un delito perfectamente social, comprendido en la amnistía promulgada por el Gobierno de la República» ${ }^{56}$

Y así lo solicitó Domínguez en un escrito que el 16 de abril dirigía al Auditor de Guerra de la Segunda División, pero la respuesta que encontró no pudo ser más desalentadora para él. El mismo día que entraba su escrito en la Auditoría de Guerra, el fiscal de la misma presentaba su informe. Descartaba que los delitos que se le imputaban - insulto de obra a la fuerza armada y asesinato- tuvieran «un origen político-social» que permitiera incluirlo en la citada disposición. Por tanto, rechazaba que se le aplicara cualquier beneficio y pedía que se elevara la causa a la Sala Sexta del Tribunal Supremo para que ésta adoptara la resolución que estimara pertinente ${ }^{57}$. Así se hacía y casi dos meses después, el 12 de junio esta Sala dictaba su fallo ratificando lo que previamente habían acordado tanto el fiscal de la Auditoría de Guerra como la Fiscalía General de la República, en el sentido de que en los hechos en los que había participado

54 Tierra y Libertad (27 de marzo de 1936), p. 4. Antes, el 6 de marzo había encabezado su portada con el siguiente titular a tres columnas: «No hay razón para excluir de la amnistía a los encartados en los llamados delitos comunes, la mayor parte de los cuales tienen un origen directo en la miseria de que es causante el régimen actual. Las rejas deben abrirse de par en par para todos los presos. Exigimos la inmediata libertad de todas las víctimas del régimen capitalista».

55 ATMT2, legajo 124, Documento n. ${ }^{\circ}$ 4122, p. 186.

56 Solidaridad Obrera (19 de marzo de 1936), p. 9.

57 ATMT2, legajo 115, documento n. ${ }^{\circ}$ 3484, p. 143. 
el encausado no se advertía «motivación política, ni social», por lo que se le denegaban los beneficios del decreto-ley de amnistía. Y es que, como escribiría varias décadas más tarde su compañero Miguel Vega en sus memorias, refiriéndose al atentado contra el guardia civil en Jerez, fue una ligereza «producto» de «aquellos tiempos [que] así eran: represiones bestiales y venganzas que se imponían ${ }^{58}$.

Juan Domínguez veía como su prisión provisional se mantenía y el 18 de julio le cogía detenido bajo la tutela del Juez Instructor Militar de la plaza de Jerez. Con toda la guarnición militar adherida al golpe fascista, la ciudad no tardó en ser controlada por las fuerzas facciosas y las milicias paramilitares de falangistas y carlistas. Las autoridades republicanas serían rápidamente detenidas y encarceladas y los asesinatos no tardaron en llegar. Una de las primeras víctimas fue Juan Domínguez, al que se le aplicaba la llamada «ley de fugas» el 14 de agosto ${ }^{59}$.

\section{Conclusiones}

Los dos tiroteos de Jerez y Arcos protagonizados por tres pistoleros vinculados a los círculos anarquistas jerezanos y que se saldaron con cuatro muertos y tres heridos fueron unos sucesos utilizados por las distintas opciones políticas del momento en función de sus propios intereses dado el cercano momento electoral que se vivía. Las derechas, como hemos visto, no tardaron en culpabilizar a las izquierdas de los mismos, presentándolos como un anticipo de lo que podría significar el triunfo del Frente

58 Vega, s/f, p. 100.

59 ATMT2. En el legajo 115, documento n. ${ }^{\circ}$ 3483, p. 162, se conserva un escrito que dirige a los gobernadores militar y civil de la provincia un capitán de la Guardia Civil de la Comandancia de Cádiz el 14 de agosto de 1936. Contaba que por orden del Juez Instructor Eventual Militar de Jerez se había ordenado el traslado desde la cárcel jerezana al cercano Penal de El Puerto. Ya en la carretera, cuando se encontraba en el kilómetro ocho de la misma, el vehículo que conducía al preso fue objeto de «una agresión por disparos de armas de fuego». En la confusión, el detenido intentó darse a la fuga, «por lo que hubo necesidad de hacerle un disparo (...) que le causó la muerte instantánea, continuando la fuerza en la busca y persecución de los agresores, no consiguiendo dar alcance a ninguno de ellos porque huyeron favorecidos por los accidentes del terreno». No era verdad, porque en el cuaderno que el carpintero José Sánchez Barrios fue anotando los nombres de todas las personas que iban siendo asesinadas en Jerez en las primeras semanas de la guerra y hoy depositado en el Archivo Municipal de la ciudad, Juan Domínguez Bustillo aparece como asesinado este mismo día 14 de agosto. Sobre este cuaderno: García Cabrera-Orellana, 2011, pp. 81-82. 
Popular en las elecciones convocadas para el mes siguiente. Por su parte, el republicanismo moderado de Arcos, representado por el alcalde Andrés Escot, enfrentado a los libertarios por haberles arrebatado éstos en 1931 su influencia en el sindicato «Fraternidad Obrera», no tardó en situar la autoría intelectual del atentado en «exterminadoras y malsanas doctrinas», en lo que era una clara referencia al anarquismo. Más tarde fueron los propios anarcosindicalistas los que utilizaron estos hechos para seguir con sus denuncias acerca de las persecuciones que decían sufrir por parte del Estado. De esta manera, como se ha contado, el cenetista «Comité Pro Presos» de Jerez llegó a poner el caso del pistolero superviviente como ejemplo de otros muchos revolucionarios que eran acosados por las fuerzas del orden. Y en 1938 les tocó el turno a los poderes fascistas de Arcos, que controlaban la ciudad desde el 19 de julio de 1936 y que no dudaron en culpabilizar a los jornaleros libertarios sindicados de la muerte del alférez Díaz para justificar su alzamiento y el exterminio de éstos.

Interpretaciones interesadas y poco rigurosas basadas en una distorsión de los acontecimientos que se ha seguido reproduciendo en la reciente historiografía. Y es que, como hemos intentado poner en evidencia, ambos atentados no tuvieron nada que ver con la violencia política y a pesar su raíz «social», por la filiación confederal de sus autores, parece claro que estas acciones habría que situarlas en el ambiguo mundo que había entre la violencia social y la delincuencia común en el que se movían estos grupos de pistoleros. El primero, el de Jerez, porque su móvil fue una venganza personal, no tuvo ningún objetivo político, ni tuvo detrás ningún conflicto laboral, a pesar de que sus autores estaban relacionados con los círculos anarquistas locales, y el segundo porque se comete de forma espontánea en un contexto de fuga y persecución cuando los pistoleros iban a ser detenidos en una taberna de Arcos.

El hecho de que estos sucesos tuvieran lugar cuando apenas faltaba un mes para las elecciones de mediados de febrero ha llevado a algunos autores a considerarlos como una clara manifestación de la violencia política que acompañaría a la campaña electoral. Es más, a Álvarez Tardío y Villa García les parecen tan relevantes que no dudan en incluirlo en una página del primero de los cuatro cuadernillos de imágenes e ilustraciones que tiene su libro sobre las elecciones del Frente Popular con el siguiente comentario:

«El 18 de enero de 1936 dos pistoleros anarquistas realizan un atentado en Jerez de la Frontera que causa dos muertos. Poco después tirotean a la Guardia Civil y matan a un teniente, antes de morir en el intercambio de disparos». 
Y remataban: «La violencia política durante la campaña fue mucho más grave de lo que se había supuesto hasta ahora» y, como era un caso que les parecía «especialmente sonado», lo volvían a contar otra vez en la página $262^{60}$. Sin embargo, como hemos intentado demostrar, estos dos incidentes sangrientos nada tuvieron de violencia política, ni siquiera de lo que pudiéramos calificar de violencia social. Así lo consideró el propio Gobierno, cuyo presidente no dudó en salir en defensa de la Guardia Civil, al día siguiente de los mismos, refiriéndose a sus atacantes como unos simples «criminales» ${ }^{61}$. Y tampoco vieron ningún contenido político, ni social las autoridades militares y judiciales que tuvieron que informar sobre la petición de amnistía que hizo el único superviviente del grupo. Es más, ni siquiera sus supuestos compañeros de la CNT arcense compartían este tipo de acciones como puso en evidencia el comunicado que lanzaron a la calle poco después de ocurrir los hechos y el propio testimonio del entonces secretario de esta sociedad obrera.

Así, creemos que estas dos circunstancias cuestionan la inclusión de estos sucesos de Jerez y Arcos en algunos de los estudios cuantitativos que recientemente se han publicado sobre la violencia política y social del primer semestre de $1936^{62}$. En primer lugar, porque su carácter «social» no puede ser más difuso, cuando todo comenzó como un «ajuste de cuentas» de uno de los pistoleros contra el guardia civil que lo había detenido anteriormente, fuera de cualquier contexto político y laboral. Estaba claro que era más una venganza personal que otra cosa, en la que también participan sus dos jóvenes cómplices muertos en Arcos. Y, en segundo lugar, porque como hemos intentado poner en evidencia, en las actuaciones de estos «grupos de acción» o bandas armadas relacionadas con el movimiento anarcosindicalista, se mezclaban actos que tenían un claro contenido «social» cuando se hacia dentro de un conflicto laboral o huelguístico, con otros de tipo estrictamente particular que entraban de lleno en el campo de la delincuencia común por ser delitos ordinarios contemplados en el entonces vigente código penal. En este caso, como atestiguaba, por ejemplo, el dinero que llevaban producto de un atraco previo, según contó

60 Álvarez Tardío-Villa García, 2017, p. 262. Ahora, lo presentaban como «la muerte de dos anarquistas en Arcos de la Frontera» y lo explicaban comentando que se había producido después que los mismos hubieran perpetrado un atentado en Jerez de la Frontera, en el que había muerto un guardia municipal y un obrero. Un error, porque el guardia no murió sino que resultó herido, como hemos contado.

61 Ahora (19 de enero de 1936), p. 1.

${ }^{62}$ La más reciente: González, 2015. 
el pistolero que sobrevivió. Finalmente, lo que pone de manifiesto este ejercicio de historia local, que pretende manejar todas las fuentes documentales disponibles, es que un análisis detallado de estos incidentes permite completar una realidad que siempre es bastante más compleja de lo que recogen las fuentes hemerográficas o bibliográficas más genéricas.

Por tanto, consideramos que existen motivos suficientes para cuestionar la calificación de actos de violencia política o sociopolítica dada a muchos incidentes de orden público de estos meses republicanos. Y es que, como hemos demostrado, regirse básicamente por la vinculación sindical o política de los participantes en un determinado incidente para luego adscribir sus delitos a una causa política o social no resulta ser eficaz. Menos aún cuando estos actos parecen ser acciones ligadas a la delincuencia común o cercanas a ésta, por sus motivaciones estrictamente personales. No delimitar claramente estos ámbitos, pese a la ambigüedad en la que se movían sus actores, supone mantener el relato interesado y catastrofista de las derechas antirrepublicanas de los años treinta, e ignora a sabiendas los grandes avances que se han producido en el estudio de estos temas en las últimas décadas, así como las complejidades y los matices que tenían muchos de los conflictos en la convulsa España de 1936.

\section{Fuentes}

Archivo Histórico Municipal de Arcos de la Frontera.

Archivo y Biblioteca Municipal de Jerez de la Frontera.

Archivo del Tribunal Militar Territorial Número 2. Sevilla.

Biblioteca Virtual de Andalucía.

Biblioteca Virtual de Prensa Histórica.

Centre de Documentació Antiautoritari i Llibertari (CEDALL)

Hemeroteca Digital. Biblioteca Nacional del España

Hemeroteca Municipal de Madrid.

Entrevistas: Antonio Rosado Peña, de 74 años (realizada el 13 de junio de 2019), y Antonia Rodríguez Oca, de 90 años (realizada el 3 de agosto de 2015).

\section{Bibliografía}

AlCAlde, Juan J., Tiempos de plomo. Grupos de Acción y Defensa Confederal, Madrid, Fundación Salvador Seguí Ediciones, 2013.

ÁLVAREZ CHILLIDA, Gonzalo, «Negras tormentas sobre la república. La intransigencia libertaria» en Rey, Fernando del (dir.), Palabras como puños. La in- 
transigencia política en la Segunda República española, Madrid, Tecnos, Madrid, 2011, pp.

ÁlVAREZ JUNCO, José, La ideología política del anarquismo español, Madrid, Siglo XXI, 1991, segunda edición.

ÁlVAREZ TARDío, Manuel y Roberto VILLA, 1936. Fraude y violencia en las elecciones del Frente Popular, Madrid, Espasa Calpe, 2017.

ARÓSTEGUI, Julio, «Conflicto social e ideología de la violencia, 1917-1936», en García Delgado, José Luis (editor), España, 1898-1936, Madrid, Ediciones de la Universidad Complutense, 1984, pp. 309-343

BOWERs, Claude G., Misión en España, Barcelona, Grijalbo, 1977.

BRENAN, Gerald, El laberinto español, Barcelona, Ibérica de Ediciones y Publicaciones, 1977.

BUESO, Adolfo, Recuerdos de un cenetista, Barcelona, Editorial Ariel, 1976.

CARO, Diego, Violencia política y luchas sociales: la Segunda República en Jerez de la Frontera (1931-1936), Jerez de la Frontera, Ayuntamiento, 2001.

CARRETERO, José Luis, Eduardo Barriobero, Madrid, Queimada ediciones, 2017.

CASANOVA, Julián, De la calle al frente, Barcelona, Crítica, 1997.

CRUZ, Rafael, En el nombre del pueblo, Madrid, Siglo XXI, 2006.

EALHAM, Chris, La lucha por Barcelona. Clase, cultura y conflicto, 1898-1937, Madrid, Alianza, 2005.

FONTECHA, Antonio, «Anarcosindicalismo y violencia: la «gimnasia revolucionaria» para el pueblo», Historia Contemporánea, 1994, 11, pp. 153-179.

garcía CABrera, José y Cristóbal Orellana (coords.), Memoria Histórica y represión franquista en la provincia de Cádiz, Cádiz, Diputación de Cádiz, 2011.

GARCÍA OLIVER, Juan, El eco de los pasos, Barcelona, Ruedo Ibérico, 1978.

GONZÁLEZ CALLEJA, Eduardo, «La historiografía sobre la violencia política en la

Segunda República; una reconsideración», Hispania Nova, 2013. Consulta realizada el 16 de mayo de 2019.

GONZÁlEZ CALLEJA, Eduardo, Cifras cruentas. Las víctimas mortales de la violencia sociopolítica de la Segunda República española (1931-1936), Granada, Comares, 2015.

GONZÁlEZ CALLEJA, Eduardo y Álvaro RIBAGORDA, La historiografía sobre la Segunda República española, Madrid, Biblioteca Nueva, 2017.

GONZÁleZ CALlEJA, Eduardo, «Revisando el revisionismo. A propósito del libro 1936. Fraude y violencia en las elecciones del Frente Popular», Historia Contemporánea, 58, 2018, pp. 851-881.

GUTIÉRREZ, José Luis, Crisis burguesa y unidad obrera. El sindicalismo en Cádiz durante la Segunda República, Madrid, Madrid Tierra/Fundación Anselmo Lorenzo, 1994.

HERRERÍN, Ángel, «El insurreccionalismo anarquista durante la Segunda República», Bulletin d'Histoire Contemporaine de l'Espagne, 51, 2015, pp. 101-117. 
¿Violencia política o delincuencia común? Los sucesos de Jerez y Arcos de principios...

HERRERín, Ángel, Camino a la anarquía. La CNT en tiempos de la Segunda República, Madrid, Siglo XXI, 2019.

JULIÁ, Santos (dir.), Violencia política en la España del siglo XX, Madrid, Taurus, 2000.

MARINELlO, Juan Cristóbal, «Los delitos sociales en la España de la Restauración (1874-1931)», Anuario de Historia del Derecho Español, LXXXVI, 2016, pp. 521-545.

MARINELlO, Juan Cristóbal, «Las izquierdas y la delincuencia político-social durante la Segunda República», en La Segona República. Cultures i projectes politics. Congrés Internacional d'Historia, Bellatera, Dipósit digital de documents de la UAB, 2016; https://ddd.uab.cat/record/148276 Consulta realizada el 10 de mayo de 2019.

MACARro, José Manuel, La utopía revolucionaria, Sevilla, Caja de Ahorros de Sevilla, 1985.

MIR, Miquel, Diario de un pistolero anarquista, Barcelona, Ediciones Destino, 2009

NúÑEZ, Jesús, La Comandancia de la Guardia Civil de Cádiz en la Guerra Civil de España (1936-1939), Madrid, UNED, 2016, Tesis doctoral inédita. Acceso abierto en: e-spacio.

PÉREZ REGORDÁn, Manuel, La historia de Arcos a través de sus calles, Arcos, Delegación de Cultura de Arcos de la Frontera, 2002.

PESTANA, Ángel, Trayectoria sindicalista, Madrid, Ediciones Tebas, 1974.

PICH, Josep, David Martínez y Xavier Casals, «Els gángsters de la FAI. Justo Bueno Pérez», Afers, 89, 2018, pp. 135-164.

Porcel, Baltasar, La revuelta permanente, Barcelona, Editorial Planeta, 1978.

REY, Fernando del, Paisanos en lucha. Exclusión política y violencia en la Segunda República española, Madrid, Biblioteca Nueva, 2008.

RIVAS, Fernando, El Frente Popular, Madrid, Librería Editorial San Martín, 1976. SOUTHWORTH, Herbert R., El lavado de cerebro de Francisco Franco: conspiración y guerra civil, Barcelona, Crítica, 2000.

TEMBLADOR LÓPEZ, Manuel, Recuerdos de un libertario andaluz, edición de Antonio Ortega Castillo y Alfonso Oñate Méndez, Madrid, Fundación de Estudios Libertarios Anselmo Lorenzo, 2019.

VEGA Álvarez, Miguel, Episodios personales. Reminiscencias de la Guerra Civil Española, ed. de autor, s/f.

VILLA, Roberto, «La CNT contra la República: la insurrección revolucionaria de diciembre de 1933», Historia y Política, 25, 2011, pp. 177-205.

VIÑAs, Ángel, ¿Quién quiso la guerra civil? Historia de una conspiración, Crítica, Barcelona, 2019.

\section{Datos de los autores}

Diego Caro Cancela catedrático de Historia Contemporánea de la Universidad de Cádiz se ha especializado en la historia política y social de la Andalucía 
contemporánea. Es el autor o coautor, entre otros, de los siguientes libros: La Segunda República en Cádiz: elecciones y partidos políticos (1987), Burguesía y jornaleros. Jerez de la Frontera en el Sexenio Democrático (1868-1874) (1990), La utopía racional. Estudios sobre el movimiento obrero andaluz (2001), Violencia política y conflictos sociales: la Segunda República en Jerez de la Frontera (2001), El mundo campesino en la España de los años treinta (ed.) (2009), Diccionario biográfico de parlamentarios de Andalucía, 1810-1869 (dir.) (2010), La revolución de 1868 en Andalucía (ed.) (2018) y Anarquismo, represión y campañas de prensa. Alcalá del Valle (1903-1910) (2019).

Antonio Ortega Castillo miembro del grupo de investigación HUM-557 «Élites, Notables y Pueblo" y doctorando en la Facultad de Filosofía y Letras de la Universidad de Cádiz. Ha trabajado como técnico investigador en la misma institución y también para la Diputación Provincial de Cádiz, el Ayuntamiento de Arcos, la Sociedad de Ciencias Aranzadi y distintas asociaciones de Memoria Histórica de la provincia de Cádiz. Actualmente ejerce como profesor de enseñanza secundaria de la Junta de Andalucía. Sus temas de investigación se han centrado en la historia local, social y política de la edad contemporánea y la violencia en el periodo de entreguerras, sobre los que ha publicado distintos artículos y capítulos de libro. Ha sido coeditor de las memorias de Manuel Temblador, Recuerdos de un libertario andaluz, Madrid, Fundación de Estudios Libertarios Anselmo Lorenzo, 2019. 